\title{
A new species of Paraberrapex Jensen, 2001 (Cestoda: Lecanicephalidea) from Squatina guggenheim Marini (Squatiniformes: Squatinidae) off Argentina
}

\author{
Leonardo D. Mutti ${ }^{1,2}$ and Verónica A. Ivanov ${ }^{1,2,3}$ \\ ${ }^{1}$ Instituto de Biodiversidad y Biología Experimental y Aplicada (IBBEA, CONICET-UBA), Facultad de Ciencias Exactas y \\ Naturales, Universidad de Buenos Aires, Ciudad Autónoma de Buenos Aires, Argentina; \\ ${ }^{2}$ Consejo Nacional de Investigaciones Científicas y Técnicas, Ciudad Autónoma de Buenos Aires, Argentina; \\ ${ }^{3}$ Departamento de Biodiversidad y Biología Experimental, Facultad de Ciencias Exactas y Naturales, Universidad de Buenos Aires, \\ Ciudad Autónoma de Buenos Aires, Argentina
}

\begin{abstract}
Paraberrapex atlanticus sp. n. (Cestoda: Lecanicephalidea) is described from the spiral intestine of the angel shark Squatina guggenheim Marini from coastal waters off Buenos Aires Province, Argentina. Paraberrapex atlanticus sp. n. can be distinguished from the only species described in the genus, P. manifestus Jensen, 2001 in having cocoons 5-6 times longer with more eggs per cocoon, the extension of the uterine duct, the distribution of vitelline follicles, and the size and density of microtriches on the bothridial surfaces. The presence of $P$. atlanticus sp. n. in S. guggenheim confirms the specificity of Paraberrapex Jensen, 2001 for squatiniform sharks.
\end{abstract}

Keywords: tapeworms, Paraberrapex atlanticus sp. n., southwestern Atlantic Ocean, angel sharks

Paraberrapex Jensen, 2001 was erected for Paraberrapex manifestus Jensen, 2001 from the angel shark, Squatina californica Ayres. Parabarrapex along with Aberrapex Jensen, 2001 are unique lecanicephalideans in their scolex configuration; they lack an apical organ and apical modification of the scolex proper (Jensen 2001, 2005). Despite their similarity in the scolex configuration, Paraberrapex can be distinguished from Aberrapex on the basis of a vagina that is medial in position rather than lateral throughout its length in the proglottid, an ovary that is bilobed rather than tetralobed in cross section, and acetabular surfaces covered with slender gladiate and coniform spinitriches rather than hastate spinitriches (Jensen 2001, 2005, Koch et al. 2012).

Recent molecular phylogenetic analyses suggest that lecanicephalideans lacking apical organs are the earliest diverging lecanicephalideans (Caira et al. 2014). Though Paraberrapex was the only non-apical organ-bearing genus included in these analyses, it is placed as the sister taxon to all lecanicephalideans with apical organs represented by 18 species in 11 genera (Caira et al. 2014). Paraberrapex has remained monotypic since its inception and its geographical distribution is restricted to the Gulf of California (Jensen 2001, 2005).
During a parasitological survey of tapeworms from elasmobranchs along the coast of Argentina, specimens of a new species of Paraberrapex were collected from the angular angel shark, Squatina guggenheim Marini. Previous records of lecanicephalideans from the southwestern Atlantic Ocean are restricted to a single species, Aberrapex arrhynchum (Brooks, Mayes et Thorson, 1981), from the southern eagle ray, Myliobatis goodei Garman, off Uruguay (Brooks et al. 1981, Jensen 2001, 2005). The new species of Paraberrapex is described herein, representing the first record of this genus from the Atlantic Ocean.

\section{MATERIALS AND METHODS}

Cestodes examined in this study were recovered from the spiral intestines of 13 specimens of Squatina guggenheim caught in September and November 2008 off Puerto Quequén, Buenos Aires Province, Argentina (38 53'00"S; 58 $27^{\prime} 00^{\prime \prime} \mathrm{W}$ ) (host field numbers VIPQ-11/04, AMPQ-93, AMPQ-94, AMPQ-95, AMPQ-98, AMPQ-103, AMPQ-105, AMPQ-110 and AMPQ-144), and along the continental shelf off Argentina in March 2011 (PD3-211at

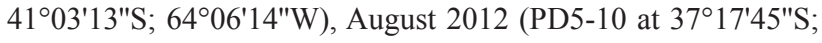
$56^{\circ} 27^{\prime} 00^{\prime \prime} \mathrm{W}$ and PD5-168 at $36^{\circ} 21^{\prime} 00^{\prime \prime} \mathrm{S}$; 54 $32^{\prime} 24^{\prime \prime} \mathrm{W}$ ), and March 2013 (PD7-515 at 4058'14"S; 6200'21"W). The specimens from Puerto Quequén were caught by commercial trawlers; 
all other specimens were caught with bottom trawls on board the Oceanographic Vessel 'Puerto Deseado' (CONICET).

All tapeworms were removed from the spiral intestine of their respective host, relaxed in seawater, fixed in $4 \%$ formalin and transferred to $70 \%$ ethanol for storage. The specimens prepared for light microscopy were hydrated in a graded ethanol series, stained with Harris' haematoxylin, dehydrated in a graded ethanol series, cleared in methyl salicylate and mounted in Canada balsam. Worms prepared for scanning electron microscopy (SEM) were hydrated in a graded ethanol series, post-fixed in $1 \%$ osmium tetroxide overnight at room temperature, dehydrated in a graded ethanol series and dried using hexamethyldisilazane. Specimens were mounted on stubs with carbon tape, coated with ca $40 \mathrm{~nm}$ of gold/palladium in a Thermo VG Scientific Polaron SC 7630 and examined in a Philips XL 30 scanning electron microscope. Shape terminology follows Clopton (2004). Terminology for the shape of microtriches follows Chervy (2009). Detached mature proglottids were embedded in paraffin and serial cross sections were cut at a thickness of $10 \mu \mathrm{m}$. Sections were stained with Harris' haematoxylin, counterstained with eosin and mounted in Canada balsam.

Gravid proglottids were opened with insect pins to free the cocoons, which were then temporarily mounted using distilled water. Whole and temporary mounts and sections were observed and measured using an Olympus BX51 compound microscope. Drawings were made with the aid of a camera lucida. Measurements are given as the range, followed in parentheses by the mean, standard deviation, number of worms examined and the total number of observations if more than one measurement per worm was taken. All measurements are in micrometres unless otherwise stated. Photographs were taken using a Nikon Coolpix 950 digital camera attached to a Zeiss Axioskop.

Museum abbreviations used are as follows: IPCAS - Institute of Parasitology, Biology Centre of the Czech Academy of Sciences, České Budějovice, Czech Republic; MACN-Pa - Museo Argentino de Ciencias Naturales, Colección Parasitológica, Buenos Aires, Argentina.

\section{RESULTS}

\section{Paraberrapex atlanticus sp. n.}

Figs. 1-3

ZooBank number for species:

urn:lsid:zoobank.org:act:A9510779-90A8-4C93-B08B-D8186D2A0BFB

Description (based on 14 worms: whole mounts of 9 complete worms, 5 strobilae without scolices, 8 mature detached proglottids and 2 gravid detached proglottids, histological sections of 2 mature proglottids and 1 gravid proglottid, 5 specimens observed with SEM and temporary mounts of 16 of cocoons). Worms $2.17-3.03 \mathrm{~mm}$ $(2.59 \pm 0.28 \mathrm{~mm}$; 9) long, maximum width at level of scolex, 15-19 (17 \pm 1 ; 9) proglottids, euapolytic (Fig. 1A). Scolex 140-200 (163 $\pm 24 ; 8)$ long, 210-300 (234 \pm 27 ; 8) wide, consisting of 4 finely deltoid acetabula (Figs. 1C, 2A). Acetabula 105-150 (127 \pm 14 ; 9) long, 103-140 (115 \pm 12 ; 9) wide. Apical modification of scolex proper and apical organ absent. Apex of scolex (Fig. 2B) and scolex proper (right half of Fig. 2F) covered with papilliform to acicular filitriches. Distal acetabular surface covered with coniform spinitriches and capilliform filitriches (Fig. 2E), proximal acetabular surface covered with slender gladiate spinitriches and acicular to capilliform filitriches (Fig. 2D, left half of Fig. 2F); spinitriches denser on proximal than distal acetabular surface. Strobila covered with acicular to capilliform filitriches transitioning into small scolopate spinitriches at posterior margins (Fig. 2C). Cephalic peduncle absent.

Proglottids craspedote, non-lancinate. Immature proglottids 15-18 $(15 \pm 1 ; 9)$ in number, initially wider than long, becoming longer than wide with maturity. Only 1 mature proglottid per strobila, longer than wide (Fig. 1A), 705-1370 (1 $068 \pm 236$; 14) long, 140-220 (180 \pm 22 ; 14) wide. Mature detached proglottids $2.30-3.80 \mathrm{~mm}(3.11 \pm 0.61 \mathrm{~mm}$; 7) long, 250-395 (307 $\pm 54 ; 7)$ wide. Gravid detached proglottids 4.40-4.85 mm (4.63 $\pm 0.23 \mathrm{~mm}$; 3$)$ long, 451-610 $(535 \pm 80 ; 3)$ wide. Testes $23-40(30 \pm 4 ; 11 ; 4)$ in number, 28-63 (42 $\pm 10 ; 11 ; 4)$ long, 25-67 (43 $\pm 10 ; 11 ; 4)$ wide, distributed in 2-3 columns in dorsoventral view, extending in field from anterior margin of proglottid to cirrus-sac on poral side and to slightly posterior to genital pore on aporal side (Fig. 1A,B), 1 row deep in cross section (Fig. 1D). Vas deferens extending anteriorly along midline of proglottid from posterior to ovary, entering cirrus sac at anterodistal margin (Fig. 1B,H). External and internal seminal vesicle absent. Cirrus sac pyriform, curved anteriorly, 30-70 (44 \pm 13 ; 9) long, 33-110 (59 \pm 22 ; 9) wide in attached mature proglottids (Fig. 1B,G), 97-260 (122 $\pm 53 ; 7)$ long, $95-165(115 \pm 22 ; 7)$ wide in detached mature proglottids, containing coiled cirrus. Cirrus unarmed, 10-27 $(15 \pm 7 ; 6)$ wide at base in detached proglottids, up to 940 long when everted.

Ovary H-shaped in dorsoventral view (Fig. 1B,H), bilobed in cross section (Fig. 1E), 90-188 (153 $\pm 13 ; 5)$ long, 40-90 $(61 \pm 19 ; 5)$ wide in attached mature proglottids, 245-630 (439 $\pm 129 ; 7)$ long, 85-260 (145 \pm 58; 7) wide in mature detached proglottids. Mehlis' gland posterior to ovary, $48-65(54 \pm 7 ; 5)$ in diameter in mature detached proglottids. Vagina slender, merging with oviduct between posterior lobes of ovary, extending from ootype along median line of proglottid, opening posterior to cirrus sac into genital atrium (Fig. 1B,G,H). Genital pores lateral, irregularly alternating, $39-57 \%(49 \pm 5 ; 18)$ of proglottid length from posterior margin in attached and detached mature proglottids.

Uterus saccate, extending along midline of proglottid from slightly anterior to ovarian bridge to level of genital pore; uterine duct connecting to uterus at its anterior end (Fig. 1B,G). Vitelline follicles in 1-2 lateral bands on each lateral margin of proglottid (Fig. 1B,D-E), extending throughout entire proglottid, interrupted by cirrus sac dorsally, becoming sparse at level of ovary (Fig. 1B,H); vitelline follicles $4-5(5 \pm 0.5 ; 5 ; 3)$ long, 5-7 (6 $\pm 1 ; 5$; 3) wide in attached mature proglottids, 25-125 (50 \pm 18 ; 7; 4) long, 15-95 (44 $\pm 22 ; 7 ; 4)$ wide in detached mature proglottids. Eggs round, packaged in elongate co- 

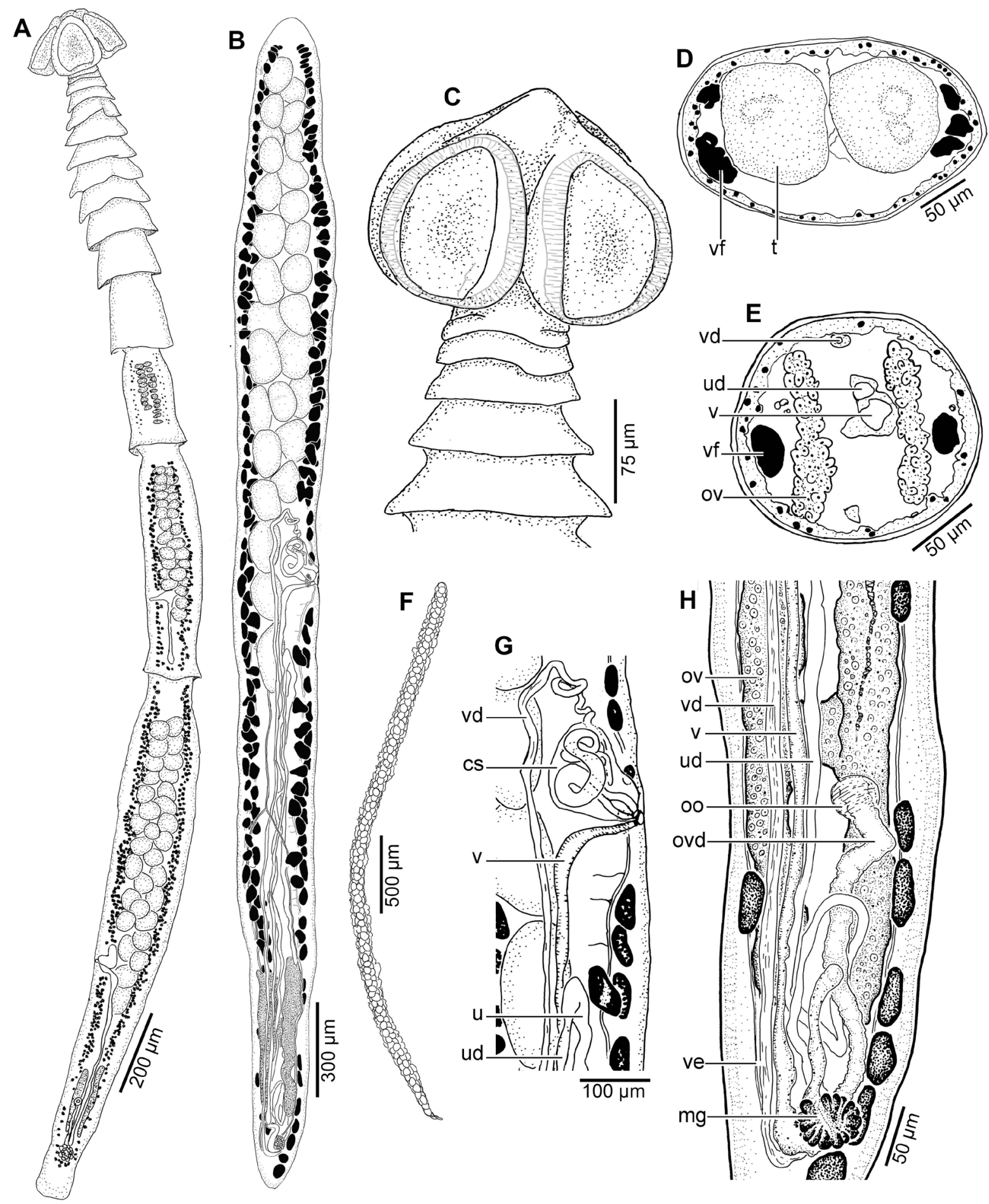

Fig. 1. Paraberrapex atlanticus sp. n. from Squatina guggenheim Marini. A - entire worm (holotype MACN-Pa No. 578/1); B - detached mature proglottid (paratype MACN-Pa No. 578/3); C - scolex (paratype MACN-Pa No. 578/2); D, E - cross section of a detached mature proglottid at level anterior to the cirrus sac (D) and at level of the ovary (E); F - cocoon with eggs; $\mathbf{G}-\operatorname{detail}$ of terminal genitalia; H - detail of ootype region of a detached proglottid. Abbreviations: cs - cirrus sac; mg - Mehlis' gland; oo - oocapt; ov - ovary; ovd - oviduct; $\mathrm{t}$ - testis; $\mathrm{u}$ - uterus; ud - uterine duct; v - vagina; vd - vas deferens; ve - vas efferens; vf - vitelline follicle.

coons of 129-229 (169 $\pm 30 ; 16)$ oncospheres arranged in 2-3 columns (Figs. 1F, 3A-C). Cocoons 2.64-4.19 mm (3.45 $\pm 0.50 \mathrm{~mm} ; 16)$ long, 60-75 $(65 \pm 5 ; 16)$ wide.

Type host: Squatina guggenheim Marini (Squatiniformes: Squatinidae).

Type locality: Off Puerto Quequén, Buenos Aires Province, Argentina $\left(38^{\circ} 53^{\prime} 00^{\prime \prime} \mathrm{S} ; 58^{\circ} 27^{\prime} 00^{\prime \prime} \mathrm{W}\right)$.
Additional localities: Near Río de la Plata estuary $\left(36^{\circ} 21^{\prime} 00^{\prime \prime} \mathrm{S} ; 54^{\circ} 32^{\prime} 24^{\prime \prime} \mathrm{W}\right)$, off Villa Gesell (371' $45^{\prime \prime} \mathrm{S}$; $\left.56^{\circ} 27^{\prime} 00^{\prime \prime} \mathrm{W}\right)$, off Carmen de Patagones (4058'14"S;

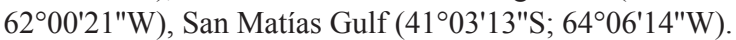

Site of infection: Spiral intestine.

Specimens deposited: Holotype MACN-Pa No. 578/1, 6 paratypes MACN-Pa No. 578/2-7 (entire worms, cross sections of detached mature proglottids and cocoons), 4 paratypes 

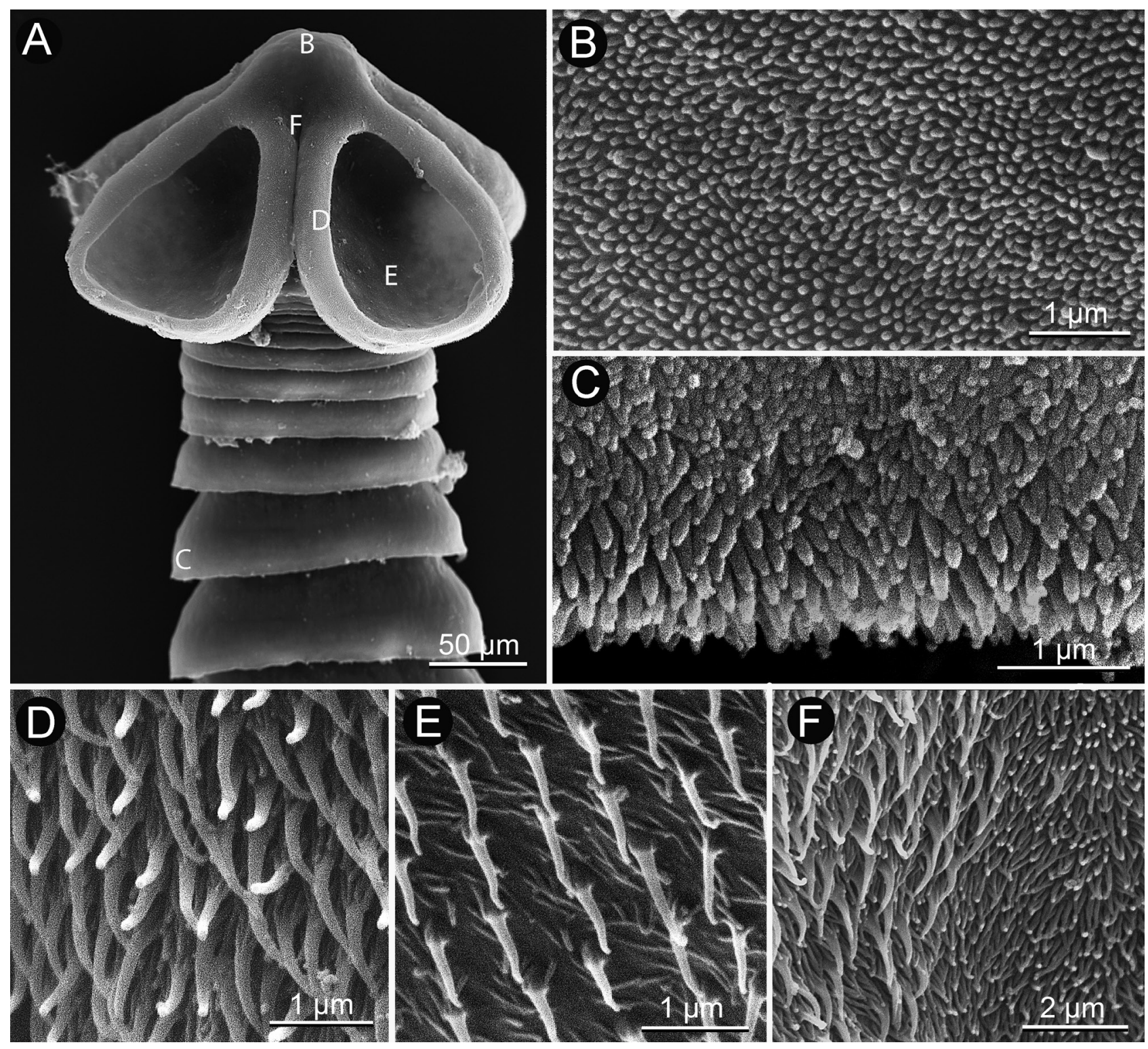

Fig. 2. Paraberrapex atlanticus sp. n. from Squatina guggenheim Marini, scanning electron micrographs. A - scolex and most anterior immature proglottids; small letters indicate locations of details shown in Fig. 2B-F; B - apex of scolex; $\mathbf{C}$ - posterior margin of immature proglottid; D - proximal acetabular surface; $\mathbf{E}$ - distal acetabular surface; $\mathbf{F}$ - scolex proper (right) and proximal acetabular surface (left).
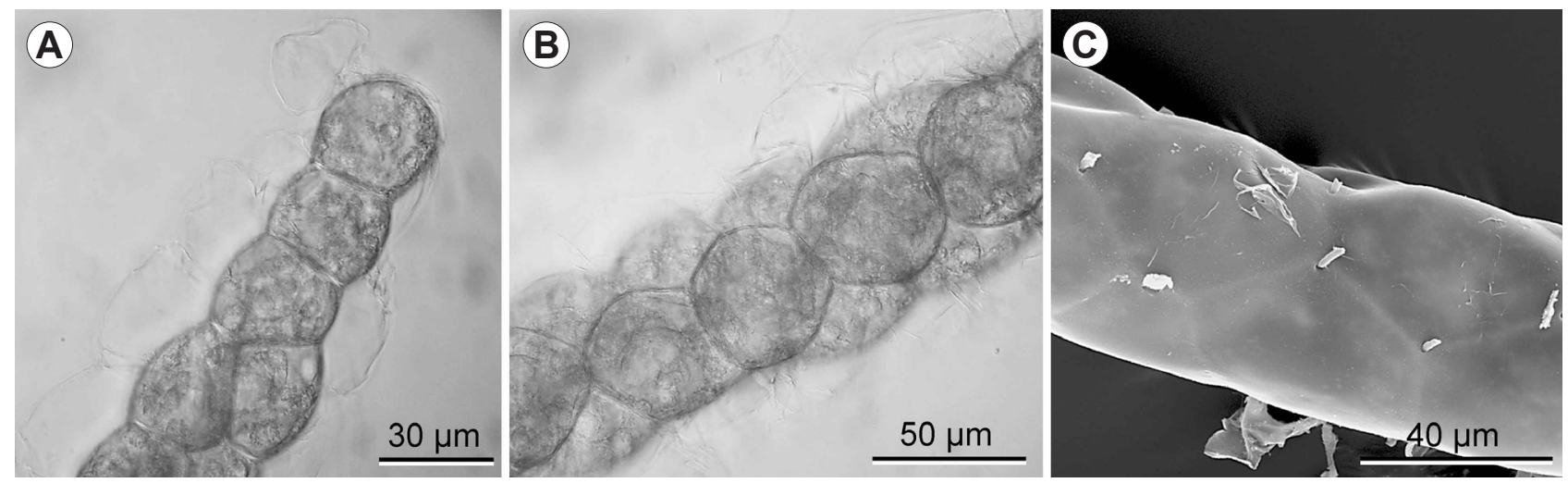

Fig. 3. Cocoons of Paraberrapex atlanticus sp. n. from Squatina guggenheim Marini. A, B - light micrographs of terminal end (A) and middle region (B); $\mathbf{C}$ - scanning electron micrograph showing detail of cocoon surface. 
(entire worms, cross sections of detached mature proglottids and cocoons) IPCAS C-702. Additional specimens (whole mounts, histological sections and specimens prepared for SEM) retained in the personal collection of Verónica Ivanov.

Prevalence : $92 \%$ (12 of 13 individuals examined infected).

Etymology: The name of this species refers to its distribution, being this the first record of the genus in the Atlantic Ocean.

Remarks. Paraberrapex atlanticus sp. n. is consistent with the generic diagnosis of Paraberrapex by having a scolex without apical modification of the scolex proper or an apical organ, proglottids without postvaginal testes, a bilobed ovary in cross section, and a vagina that runs along the midline of the proglottid. Paraberrapex atlanticus can be distinguished from $P$. manifestus in having cocoons that are 5-6 times longer (2.6-4.2 $\mathrm{mm}$ vs $0.5-0.7 \mathrm{~mm})$, with a greater number of eggs per cocoon (129-229 vs 69-112). In addition, in $P$. atlanticus the uterine duct joins the uterus at its anterior end rather than at about half of the length of the uterus (38-78\% of uterus length from the posterior end). The vitelline follicles are interrupted dorsally at the level of cirrus sac in $P$. atlanticus, whereas they are uninterrupted in P. manifestus. Whereas the microthrix pattern in both species is similar overall, the filitriches on the distal and proximal bothridial surfaces are conspicuously longer and the spinitriches are less dense in P. manifestus.

\section{DISCUSSION}

The vast majority of lecanicephalidean diversity is in the Indo-Pacific region (Jensen 2005, 2006, Koch et al. 2012, Mojica et al. 2013, 2014, Cielocha et al. 2014). Generic and species diversity is greatest in tropical waters, diminishing in temperate zones (Jensen 2005), and no records of lecanicephalideans exist in cold waters. With the description of Paraberrapex atlanticus the distribution of Paraberrapex is expanded from the eastern Pacific Ocean to also include the southwestern Atlantic Ocean. Previous to this study, there was a single record of a lecanicephalidean from off the coast of Uruguay, Aberrapex arrhynchum.

The limited reports of lecanicephalideans in this area could be related to a gap in lecanicephalidean distribution, lack of studies, lack of suitable hosts or a combination of them all. Lecanicephalideans are mainly parasites of batoids, although a few species have been reported from sharks (Caira et al. 1997, Jensen 2005). They have been found in all batoid orders, except in Rajiformes, with great generic diversity in Dasyatidae and Myliobatidae (Caira and Jensen 2014). Most batoids along the coast off Argentina are rajiform skates (69\%) (Cousseau et al. 2010), unsuitable hosts for lecanicephalideans. However, there are at least 19 species of elasmobranches in 4 orders (i.e. Myliobatiformes, Rhinopristiformes, Squatiniformes and Torpediniformes) that might be good candidates to host lecanicephalideans.

On the basis of recent collections of elasmobranchs in the Argentine Sea, lecanicephalideans have not been found from several specimens of Discopyge tschudii Heckel (Torpediniformes) and Zapteryx brevirostris (Müller et
Henle) (Rhinopristiformes), although putative novel species of Aberrapex have been collected from M. goodei and M. ridens Ruocco, Lucifora, Díaz de Astarloa, Mabragaña et Delpiani. Intensive collections in this area are providing evidence that the diversity of lecanicephalideans has been underestimated.

The genera reported from the southwestern Atlantic, Aberrapex and Paraberrapex, share a unique scolex morphology for a lecanicephalidean, lacking an apical organ and apical modification of the scolex proper. Whereas species of Aberrapex are parasites of Myliobatiformes in the genera Myliobatis Cuvier, Taeniura Müller et Henle and Aetomylaeus Garman (see Jensen 2001, 2006, Koch et al. 2012), Paraberrapex is restricted to Squatiniformes (Jensen 2001, 2006): Paraberrapex manifestus is a parasite of Squatina californica in the Gulf of California, and $P$. atlanticus was found in S. guggenheim off Argentina. Among the 22 valid species of Squatina Dumèril (see Vaz and De Carvalho 2013, Froese and Pauly 2015), only five species have been reported as parasite hosts. These are, in addition to $S$. californica and $S$. guggenheim, $S$. japonica Bleeker, S. squatina (Linnaeus) and S. australis Regan (see Yamaguti 1934, Williams 1968, Beveridge and Campbell 2001, Palm 2004). However, no species of Paraberrapex have been reported from these latter three species.

The presence of species of Paraberrapex in both $S$. californica and S. guggenheim is quite interesting. Stelbrink et al. (2010) carried out a comprehensive phylogenetic reconstruction of 17 of the 22 species of Squatina based on molecular sequence data. The phylogenetic hypotheses resulting from the analyses showed Squatina monophyletic. Moreover, Stelbrink et al. (2010) recognised four geographic clades: (1) European, North African and Asian species, (2) South African species, (3) Australian species, and (4) North and South American species. Their American clade (Clade 4) included five species: $S$. armata (Philippi) (southeastern Pacific), S. californica (northeastern Pacific), S. dumeril Lesueur (northwestern Atlantic), S. guggenheim and S. occulta Vooren et da Silva (southwestern Atlantic) (Stelbrink et al. 2010). Considering that most species of Squatina occur in small areas and transoceanic migrations are thought to be extremely unlikely (see Stelbrink et al. 2010), and that, to date, Paraberrapex has been only reported from species of Squatina in the western hemisphere, it is possible that Paraberrapex is restricted to the waters surrounding North and South America. Curiously, the trypanorhynch species Grillotia (C.) carvajalregorum Menoret et Ivanov, 2009 has also been reported from $S$. californica and $S$. guggenheim in the northeastern Pacific and the southwestern Atlantic, respectively (see Menoret and Ivanov 2009, 2012, Beveridge and Campbell 2010). Actually, G. (C.) carvajalregorum co-occurs with $P$. atlanticus, being collected from the same host individuals. It would be interesting to generate molecular sequenced data for specimens of $G$. (C.) carvajalregorum from different hosts and areas of distribution to corroborate its identity as a single species or to reveal the presence of cryptic species. 
If Paraberrapex is in fact restricted to western species of Squatina in the hemisphere, it would be expected to find at least seven more species in this genus, one in each of the seven remaining species of Squatina occurring off North and South America.

Acknowledgements. The authors are grateful to Adriana Menoret (IBBEA-CONICET-UBA) for her assistance in the field, and to Juan M. Díaz de Astarloa, Ezequiel Mabragaña, Matías Delpiani and Daniel Bruno (Universidad Nacional de Mar del PlataCONICET) for their help in the identification of hosts collected on board of the RV 'Puerto Deseado'. We would also like to thank Gustavo Chiaramonte, who made laboratory facilities at the
Estación Hidrobiológica Quequén, Museo Argentino de Ciencias Naturales - CONICET available to us, and Jorge Pérez Comesaña and Leonardo Tamini for their invaluable help in the field. This work has been funded by grants UBACyT 20020130100617BA (2014-2017) from Universidad de Buenos Aires (Argentina), PIP No. 236 from Consejo Nacional de Investigaciones Científicas y Técnicas (CONICET, Argentina) and PICT No. 2358 (2015-2018) from Agencia Nacional de Promoción Científica y Tecnológica (Argentina) to VAI. This study was conducted under collecting permit No. 39 from the Dirección Provincial de Pesca-Ministerio de Asuntos Agrarios de la Provincia de Buenos Aires, Argentina.

\section{REFERENCES}

Beveridge I., CAmpbell R.A. 2001: Grillotia australis n. sp. and G. pristiophori n. sp. (Cestoda: Trypanorhyncha) from Australian elasmobranch and teleost fishes. Syst. Parasitol. 49: 113-126.

Beveridge I., Campbell R.A. 2010: Validation of Christianella Guiart, 1931 (Cestoda: Trypanorhyncha) and its taxonomic relationship with Grillotia Guiart, 1927. Syst. Parasitol. 76: 111-129.

Brooks D.R., Mayes M.A., Thorson T.B. 1981: Cestodes parasites in Myliobatis goodei Garman (Myliobatidae, Myliobatiformes) from Río de la Plata, Uruguay, with a summary of cestodes collected from South American elasmobranch during 1975-1979. Proc. Biol. Soc. Wash. 93: 1239-1252.

Caira, J.N., Jensen, K. 2014: A digest of elasmobranch tapeworms. J. Parasitol. 100: 373-391.

Caira J.N., Jensen K., Waeschenbach A., Olson P.D., LitTLEWOOD D.T.J. 2014: Orders out of chaos - molecular phylogenetics reveals the complexity of shark and stingray tapeworm relationships. Int. J. Parasitol. 44: 55-73.

Caira J.N., Jensen K., Yamane Y., Isobe A., Nagasawa K. 1997: On the tapeworms of Megachasma pelagios: description of a new genus and species of lecanicephalidean and additional information on the trypanorhynch Mixodigma leptaleum. In: K. Yano (Ed.), Biology of the Megamouth Shark, Tokyo University Press, Tokyo, pp. 181-191.

Chervy L. 2009: Unified terminology for cestode microtriches: a proposal from the International Workshops on Cestode Systematics in 2002-2008. Folia Parasitol. 56: 199-230.

Cielocha J.J., Jensen K., Caira J.N. 2014: Floriparicapitus, a new genus of lecanicephalidean tapeworm (Cestoda) from sawfishes (Pristidae) and guitarfishes (Rhinobatidae) in the Indo-West Pacific. J. Parasitol. 100: 485-499.

Clopton R.E. 2004: Standard nomenclature and metrics of plane shapes for use in gregarine taxonomy. Comp. Parasitol. 71: 130140 .

Cousseau M.B., Degeneri M.A., Figueroa D.E. 2010: Fishes. In: M.B. Cousseau (Ed.), Fishes, Crustaceans and Molluscs of the Southwest Atlantic, between $34^{\circ} \mathrm{S}$ and $55^{\circ} \mathrm{S}$, with Indication of Important Fishing Species. Instituto Nacional de Investigación y Desarrollo Pesquero, Secretaría de Agricultura, Ganadería, Pesca y Alimentos, Mar del Plata, 64 pp.

Froese R., Pauly D. (Eds.) 2015: FishBase. World Wide Web electronic publication, www.fishbase.org, 12/2015.

JeNSEN K. 2001: Four new genera and five new species of lecanicephalideans (Cestoda: Lecanicephalidea) from elasmobranchs in the Gulf of California, Mexico. J. Parasitol. 87: 845-861.
Jensen K. 2005: Tapeworms of elasmobranchs (Part I). A monograph on the Lecanicephalidea (Platyhelminthes, Cestoda). Bull. Univ. Nebr. State Mus. 18: 1-241.

Jensen K. 2006: A new species of Aberrapex Jensen, 2001 (Cestoda: Lecanicephalidea) from Taeniura lymma (Forsskål) (Myliobatiformes: Dasyatidae) from off Sabah, Malaysia. Syst. Parasitol. 64: 117-123.

Koch K.R., Jensen K., Caira J.N. 2012: Three new genera and six new species of lecanicephalideans (Cestoda) from eagle rays of the genus Aetomylaeus (Myliobatiformes: Myliobatidae) from northern Australia and Borneo. J. Parasitol. 98: 175-198.

Menoret A., Ivanov V.A. 2009: New name for Progrillotia dollfusi Carvajal et Rego, 1983 (Cestoda: Trypanorhyncha): description of adults from Squatina guggenheim (Chondrichthyes: Squatiniformes) off the coast of Argentina. Folia Parasitol. 56: 284-294.

Menoret A., Ivanov V.A. 2012: Description of plerocerci and adults of a new species of Grillotia (Cestoda: Trypanorhyncha) in teleosts and elasmobranchs from the Patagonian shelf off Argentina. J. Parasitol. 98: 1185-1199.

Mojica K.R., Jensen K., Caira J.N. 2013: Revision of Anteropo$r a$ (Cestoda: Lecanicephalidea) and descriptions of five new species from stingrays (Myliobatiformes: Dasyatidae) in Borneo. Raffles Bull. Zool. 61: 491-506.

Mojica K.R., Jensen K., Caira, J.N. 2014: The ocellated eagle ray, Aetobatus ocellatus (Myliobatiformes: Myliobatidae), from Borneo and northern Australia as host of four new species of Hornellobothrium (Cestoda: Lecanicephalidea). J. Parasitol. 100: 504-515.

Palm H.W. 2004. The Trypanorhyncha Diesing, 1863. PKSPL-IPBPress, Bogor, $710 \mathrm{pp}$.

Stelbrink B., von Rintelen T., Cliff G., Kriwet J. 2010: Molecular systematics and global phylogeography of angel sharks (genus Squatina). Mol. Phylogenet. Evol. 54: 395-404.

Vaz D.F., De Carvalho M.R. 2013: Morphological and taxonomic revision of species of Squatina from the southwestern Atlantic Ocean (Chondrichthyes: Squatiniformes: Squatinidae). Zootaxa 3695: $1-81$.

Williams, H.H. 1968: The taxonomy, ecology and host-specificity of some Phyllobothriidae (Cestoda: Tetraphyllidea), a critical revision of Phyllobothrium Beneden, 1849 and comments on some allied genera. Phil. Trans. R. Soc. London 253: 231-307.

Yamaguti S. 1934: Studies on the helminth fauna of Japan. Part 4. Cestodes of fishes. Jpn. J. Zool. 6: 1-112.

Cite this article as: Mutti L.D., Ivanov V.A. 2016: A new species of Paraberrapex Jensen, 2001 (Cestoda: Lecanicephalidea) from Squatina guggenheim Marini (Squatiniformes: Squatinidae) off Argentina. Folia Parasitol. 63: 007. 